\title{
Building personal resilience in paramedic students
}

\author{
Gregory S. Anderson, ${ }^{\star}$ Adam D. Vaughan, ${ }^{*}$ and Steven Mills*
}

\begin{abstract}
The present study examined the impact of a 6- to 8-hour, self-paced online resiliency training program to help students training to be Primary Care Paramedics (PCP) mitigate the risks associated with working in a trauma informed work setting. Of the 138 participants, 88 were male and 30 were female, with a mean age of 25.5 years. Of these, 81 students participated in the experimental group (who took the course), and 57 in the control group. Baseline demographic results were examined using bivariate comparisons between the control and experimental, and all were found to be statistically insignificant at $p<0.05$ which suggests that there were no differences between the two groups on the pre-test demographic variables. Prior to the intervention there were no significant differences in total resilience or any of the sub-scales (selfreliance, meaningfulness, equanimity, perseverance, and existential aloneness). Following the resiliency training and the practicum experience, the experimental group scored better in total resilience and each of the sub-scores $(p<0.05)$ except meaningfulness. Results suggest that developing skills to mitigate and manage workplace trauma can reduce or help mitigate the negative impact of exposure to trauma and potentially reduce the risk of developing trauma related mental health problems which may impact the well-being and quality of life of students once employed as a paramedic.
\end{abstract}

Key Words Prevention; online learning; coping; trauma; PTSD; PTSI

Journal of CSWB. 2017 June;2(2):51-54

www.journalcswb.ca

\section{INTRODUCTION}

Recent research suggests that paramedics may be at increased risk for developing work-related health issues. In a review of the literature paramedics were found to have an increased prevalence of early retirement based on medical grounds, a greater frequency of musculoskeletal injuries, and an increased prevalence of post-traumatic stress and anxiety (Sterud, Ekeberg, \& Hem, 2006). While Berger et al. (2012) found a pooled prevalence of post-traumatic stress disorder (PTSD) of $10 \%$ in rescue workers, it was highest in paramedics (14.6\%); other studies have reported the incidence to range between 20-26\% (Regehr, Goldberg, \& Hughes, 2002; Sterud et al., 2006). With such variability in the prevalence of PTSD in the paramedic community (as well as other first responder groups), there has yet to be any empirical evidence or estimates as to the psychosocial and financial impact of PTSD (Wilson, Guliani, \& Boichev, 2016). However, it seems clear from the limited research to date that the stressors associated with ambulance work may lead to increased mental health concerns, short- and long-term disability (Leblanc et al., 2012).

While paramedics play a central role in pre-hospital care, in the assessment, management, treatment, and transportation of patients, the educational programs for paramedics appear "somewhat preoccupied with the technical and physical aspects of varying trauma management" (Williams, 2013: 207). Yet, significant stress and/or PTSD can significantly impair one's ability to function in such complex environments, significantly impacting work performance and quality of life (Lopez, 2011). Coupled with the fact that there is a lack of evidence to suggest that crisis-focused psychological intervention programs effectively reduce PTSD (Beshai \& Carleton, 2016), alternative options for proactive and reactive responses have been suggested. One option, as suggested by Gayton and Lovell (2012), is for increased attention to be paid to the development of resilience skills in paramedics and paramedic students. Without skills to mitigate and manage workplace trauma, paramedics are at risk for developing trauma related mental health problems which may impact the well-being and quality of life in retirement (Bracken-Scally, McGilloway, Gallagher et al., 2014).

The present study examined the impact of a 6- to 8-hour, self-paced online resiliency training program to help students training to be Primary Care Paramedics (PCP) mitigate the risks associated with working in a trauma informed work setting. The online curriculum aimed at teaching resiliency skills, building personal resiliency resources to be used through their practicum placements and further employment. 
It was hypothesized that a short-duration, self-paced course would increase students' resiliency throughout the program, including their practice education experience on ambulances and in hospital emergency departments.

\section{METHODS}

Using a randomized control trial, cohorts of students were randomly assigned to either the experimental (with the online course as an intervention) or control group. Two cohorts were randomly assigned to receive the online course intervention designed to build capacity for resilient behaviour, while two cohorts acted as the control group. Cohorts were campus based, and students were not at the same location for training, reducing any contamination of data.

Baseline resilience was measured in all participants using version 3.20 of the Resilience Scale (RS), a valid and reliable tool for assessing resiliency in a wide range of populations (Wagnild, 2009). Data collected included a total aggregate score, and five sub-scale scores. The subscales measure self-reliance (belief in oneself), meaningfulness (the realization that life has purpose and that there is something to live for), equanimity (a balanced life perspective that moderates extremes in emotions), perseverance (persisting behavior in the face of adversity), and existential aloneness (a realization of the uniqueness of each individual and that some experiences are independent whereas others can be processed collectively) (Wagnild, 2009). The RS is a 25-question survey that uses a 7-point Likertstyle scale. Total RS scores may range from as low 25 to as high as 175 .

A demographic survey and pre-tests of the RS were administered to all primary care paramedic (PCP) student volunteers prior to performing a practicum experience where students were placed with a mentor on normal shift rotations in an on duty ambulance. Prior to their immersive experience, students in the experimental group completed a 6- to 8-hour, self-paced resiliency training program online. The course had several learning objectives which include: defining resilience, identifying the emotional and physical risks of paramedicine work, recognizing symptoms of stress, post-traumatic stress disorder and vicarious trauma, and building resilience skills through understanding and applying techniques to manage self-talk, feelings, and behaviour. Table I provides an outline of the topics that were covered in the course.

All pre-intervention data, including the RS and informed consent, were collected during the second week of class. The intervention was conducted through a blended online format over a two week period. Post-test data were also collected using the RS following completion of the paramedic immersion in active rotation. Data were analyzed using SPSS V.23. Due to the lack of ability to pair data from pre- and post-data collection, independent sample t-tests were used to explore significant findings.

\section{RESULTS}

\section{Demographic Information}

In total, 81 students participated in the experimental group, and 57 in the control group with a total sample of 138 PCP volunteers. Baseline demographic results are highlighted for the entire sample for this study as bivariate comparisons between the control and experimental were found to be statistically insignificant at $p<0.05$ which suggests that there were no differences between the two groups on the pre-test demographic variables. Of the 138 participants, there were 88 males and 50 females. Because this study involved student paramedics, the mean age for participants was 25.5 along with 4.8 months of experience. For baseline educational experience for both the control and experimental groups, roughly $54 \%$ had a high school diploma, $27 \%$ had a post-secondary diploma from a community college or other technical institute, and about 19\% had a bachelor's degree or graduate degree. Paramedic specific training for PCP participants comprised of emergency responder (EMR) training (82\%), occupational first aid (OFAIII) (13\%), and other training experience (5\%). Lastly, with roughly $90 \%$ of the participants in this study not having any previous PCP training experience, the vast majority of did not have any professional paramedic experience prior to enrolling in their current program of study.

\section{RS Scores}

Prior to the intervention there were no significant differences in total resilience or any of the sub-scales. Following the resiliency training and the practicum experience the experimental group scored better in total resilience and each of the sub-scores $(p<0.05)$ except meaningfulness (see Table II).

\section{DISCUSSION}

Traditional first responder organizations (i.e., police officers, fire fighters, and paramedics) have known for quite some time of the potential stress and emotional impact of working in emergency situations. Such impacts can manifest into interpersonal difficulties at work and at home. Organizational responses to these situations tend to be reactive, where a

TABLE I

Building resiliency course outline

\begin{tabular}{|c|c|}
\hline Topic & Material Covered \\
\hline The Stress Story & Physiology of Stress; Mind/Body Connection \\
\hline When is stress really trauma? & Defining trauma; The faces of trauma; The culture of trauma \\
\hline Benefits and risks of being a Paramedic & Describe workplace benefits and risks; Defining vicarious traumatization \\
\hline Balancing risk and benefits with resiliency & Defining resiliency \\
\hline Managing Stress: How do I do? & Self-awareness and triggers; Support systems; Coping strategies \\
\hline Building Resiliency & Putting the pieces together; Maintaining life balance; Help-seeking behaviours \\
\hline
\end{tabular}


TABLE II Mean pre- and post-scores for the control and experimental group

\begin{tabular}{lcccccc}
\hline \multirow{2}{*}{\multicolumn{1}{c}{ RS Score }} & \multicolumn{2}{c}{ Control Group } & & \multicolumn{2}{c}{ Experimental Group } \\
\cline { 2 - 3 } \cline { 6 - 7 } & Pre & Post & & Pre & Post \\
\hline Self-reliance & 29.30 & 30.03 & & 29.00 & $37.00^{a}$ \\
Meaningfulness & 28.65 & 28.91 & & 28.06 & 31.53 \\
Equanimity & 27.59 & 28.42 & & 27.02 & $34.00^{a}$ \\
Perseverance & 28.75 & 29.12 & & 28.22 & $33.27^{a}$ \\
Existential Aloneness & 30.02 & 29.85 & & 28.25 & $36.68^{a}$ \\
\hline Total Score & 144.07 & 146.33 & & 140.56 & $173.36^{a}$ \\
\hline
\end{tabular}

a $p<0.05$

worker will be removed from active/front line duty and/ or moved to another location, their hours may be adjusted accordingly, or they may be placed on leave. In some agencies, there is an absence of a defined organizational response because the notion of occupational stress/trauma is part of the job.

In recent years, the importance of building resiliency has been used as an approach to help proactively keep emergency responders mentally well while they work and to hopefully mitigate future psychological trauma $(\mathrm{Wu}$ et al., 2013). The idea that future stress, strain, and traumatization can be prevented is certainly a major concern in these professions. As a result, various programs exist around the world, with some focusing on crisis situations, while others work towards building resiliency throughout an employee or volunteer's tenure. However, even with the breadth of programs that are available, more research is needed (Beshai \& Carleton, 2016).

The present study examined the impact of a 6- to 8-hour, self-paced online resiliency training program to help students training to be Primary Care Paramedics (PCP) mitigate the risks associated with working in a trauma informed work setting. The online intervention was designed to increase self-awareness concerning personal and work risk factors, and the signs and effects of vicarious traumatization. The training allowed students to practice and acquire evidence based behaviors and coping skills that are related to reduction or mitigation of risks associated with the development of mental health problems and substance abuse. The online course used self-reflective journaling, exercises, quizzes as well a discussion forum and Web-based self-assessment tools to engage students in learning knowledge and skills that would increase their ability to work as a paramedic while maintaining wellness throughout their career as a paramedic.

The online course was placed into the experimental group's curriculum prior to the students moving into a practicum setting where they went for the first time on shift rotations with an ambulance crew, providing a proactive approach to increasing personal resilience and coping. Results from the present study demonstrated a significant improvement in the paramedic students' resiliency following the online training. These positive results suggest that resiliency education during paramedic training programs have significant impact on students who are placed into onthe-job pre-employment training. The possibility that such training could have positive effects on preventing, reducing, and/or mitigating the risks of working in a trauma-informed work environment could result in important improvements in the quality of the working lives of first responders, and the potential short- and long-term disabilities associated with post-traumatic stress.

\section{CONCLUSIONS}

A paramedic entering a career has a $100 \%$ chance of being exposed to trauma across a wide spectrum of events. Developing, in a proactive way, skills that can improve the way that they respond personally to post-traumatic stress injury appears to help paramedic students when trained before their first ambulance experience with students in the experimental group in the present study exhibiting increased resilience as compared to the controls. Future research should extend these findings into further populations, in other professions, and in incumbents at various stages of their career.

\section{ACKNOWLEDGMENTS}

This project was partially funded by the Canadian Mental Health Association, Campus Capacity Development Grant, and partially by the Justice Institute of British Columbia. Glenda Kerr was instrumental in course design, while Jennifer Armstrong provided project management.

\section{DISCLOSURES}

The authors state that there are no conflicts of interest.

\section{AUTHOR AFFILIATIONS}

*Justice Institute of British Columbia, New Westminster, BC, Canada.

\section{REFERENCES}

Berger, W., Coutinho, E. S. F., Figueira, I., Marques-Portella, C., Luz, M. P., Neylan, T. C., . . Mendlowicz, M. V. (2012). Rescuers at risk: A systematic review and meta-regression analysis of the worldwide current prevalence and correlates of PTSD in rescue workers. Social Psychiatry and Psychiatric Epidemiology, 47(6), 1001-1011.

Beshai, S., \& Carleton, R. N. (2016). Peer support and crisis-focused psychological intervention programs in Canadian first responders: Blue Paper. Regina, SK: University of Regina Collaborative Centre for Justice and Safety. Available from: http://www.justiceandsafety.ca/resources/cipsrt

Bracken-Scally, M., McGilloway, S., Gallagher, S., \& Mitchell, J. (2014). Life after the emergency services: An exploratory study of well being and quality of life in emergency service retirees. International Journal of Emergency Mental Health and Human Resilience, 16(1), 44-61.

Gayton, S. D., \& Lovell, G. P. (2012). Resilience in ambulance service paramedics and its relationships with well-being and general health. Traumatology, 18(1), 58-64

Leblanc, V. R., Regehr, C., Tavares, W., Scott, A. K., Macdonald, R., \& King, K. (2012). The impact of stress on paramedic performance during simulated critical events. Prehospital and Disaster Medicine, 27(4), 369-374.

Lopez, A. (2011). Posttraumatic stress disorder and occupational performance: Building resilience and fostering occupational adaptation. Work, 38(1), 33-38.

Regehr, C., Goldberg, G., \& Hughes, J. (2002). Exposure to human tragedy empathy, and trauma in ambulance paramedics. American Journal of Orthopsychiatry, 72(4), 505-513

Sterud, T., Ekeberg, $\varnothing, \&$ Hem, E. (2006). Health status in the ambulance services: A systematic review. BMC Health Services Research, 6(1), 82.

Wagnild, G. M. (2009). A review of the Resilience Scale. Journal of Nursing Measurement, 17(2), 105-113 
BUILDING PERSONAL RESILIENCE, Anderson et al.

Wagnild, G. M. (2009). The resilience scale user's guide: For the US English version of the resilience scale and the 14-item resilience scale (RS-14), Guinn P. E. (editor). Resilience Center. Available from: http://www. resiliencecenter.com/

Williams, A. (2013). The strategies used to deal with emotion work in student paramedic practice. Nurse Education in Practice, 13(3), 207-212.
Wilson, S., Guliani, H., \& Boichev, G. (2016). On the economics of posttraumatic stress disorder among first responders in Canada. Journal of Community Safety \& Well-Being, 1(2), 26-31.

Wu, G., Feder, A., Cohen, H., Kim, J. J., Calderon, S., Charney, D. S., \& Mathé, A. A. (2013). Understanding resilience. Frontiers in Behavioral Neuroscience, 7(10), 1-15. 